\title{
Test of a procedure to control inter-pair learning and the effect of repeated, post-criterion test trials on retention'
}

\author{
WILLIAM E. MONTAGUE AND HAROLD n, KIESS \\ UNIVERSITY OF ILLINOIS, URBANA
}

A test was made of the effectiveness of Battig's (1965) "correction" method in controlling inter-item associative strength. Since no reliable differences were found between item recall frequencies at criterion, the method achieves its purpose. After several post-criterion tests (Ts), however, significant inter-item differences were found which may necessitate a modification of the method. The repeated $T s$, contrary to previous findings, revealed no increase in associative strength over $T s$ and had no effect on recall after three days.

In P-A learning the control of level of learning of individual pairs is critical in studies of retention (Underwood, 1964). In both the anticipation and recall method the level of learning of the pairs differs after several trials due to differences in ease of learning.

Battig (1965) used a drop-out (DO) modification of the recall or learn-test method (LT) to control interitem associative strength (IIAS) and to eliminate the confounding of learning and testing inherent in the anticipation method (ANT). After all pairs are presented, pairs correctly recalled are dropped; incorrect pairs are shown again and tested. When all pairs are recalled once, a trial is finished and the next starts with all pairs. Battig reported that DO produces faster learning than ANT or LT.

The present study examined the effectiveness of DO in balancing IIAS by comparing the associative strength of different pairs at criterion. In addition, post-criterion test (Ts) were utilized to evaluate stability of the estimate of level of learning. Previous studies (see e.g., Richardson \& Gropper, 1964) found significant improvement in recall over Ts. The use of different methods precluded extrapolation of their results to the present study.

Method

Ten groups of $15 \mathrm{Ss}$ each learned a criterion list $(A-C)$ after different kinds of prior training. An attempt was made to assess the effects of prior training on learning rate and retention. The description of the training is peripheral to this report and will be mentioned only briefly. Three groups learned two lists prior to $\mathrm{A}-\mathrm{C}$ in an $\mathrm{A}-\mathrm{B}, \mathrm{B}-\mathrm{C}$ mediation paradigm. The remaining groups were controls for non-specific transfer. To control learning-to-learn, three groups learned two lists prior to $A-C$ in a $D-E, E-F$ paradigm where the materials had no known relation to A-C. Three other groups learned the $\mathrm{C}$ items to perfect free recall to control response learning. The tenth group was a control for the combined effects of response learning and learning-to-learn. Ss learned three lists in a $\mathrm{D}-\mathrm{E}, \mathrm{E}-\mathrm{C}, \mathrm{A}-\mathrm{C}$ paradigm. The mediation groups learned significantly faster than the controls $(p<.01)$ but no significant differences were found between the control groups.

All lists were eight pairs in length. A and D items were CVCs (mean $\underline{a}^{\prime}=1.58,1.73$, Noble, 1961). The $\mathrm{C}$ and $\mathrm{F}$ items were also CVCs (mean $\left.\underline{a}^{\prime}=1.34,1.47\right)$. A high degree of physical similarity existed among the items, as can be seen for the $\mathrm{C}$ items in Table 1. The F list was constructed similarly using different consonants. The mediators (B and $\mathrm{E}$ ) were highly familiar words. The pairs and stimuli were typed on index cards and presented at a 5-sec. rate. S spelled CVCs and said words aloud.

Battig's DO was used. At the start of each DO trial a different order was used. All Ss learned $\mathrm{A}-\mathrm{C}$ to a criterion of six out of eight responses correct on an initial test $\left(\mathrm{T}_{\mathrm{c}}\right)$ when all pairs were presented. Prior lists were learned to a one-perfect-trial criterion. A warm-up (WU) task (eight letter pairs) was given for three trials prior to the first list to familiarize Ss with the task.

Groups within each prior training condition received either 0,1 or 3 Ts after reaching criterion on A-C. Group 10 received no additional Ts. All Ss returned in three days for a recall test $\left(\mathrm{T}_{\mathrm{r}}\right)$ which was preceded by WU.

\section{Results and Discussion}

As shown in Fig. 1 the performance of all groups on $\mathrm{T}_{\mathrm{C}}$ was equivalent. Analysis of variance (ANOVA) revealed no differences between the groups on any $T$. However, a significant loss in number of correct recalls was found between $T_{c}$ and $T_{1}, F=49.03, d f=1 / 84$, $\mathrm{p}<.01$. Analysis of the data for the groups receiving all three Ts revealed no further loss. Previous experiments have found consistent increases, not decreases, over repeated Ts (e.g., Richardson \& Gropper, 1964; Butler \& Peterson, 1965; Greenbloom \& Kimble, 1966). However, these studies used ANT and the latter two studied the effect of the repeated Ts on recall of list 1 in a retroaction design. In a more comparable experiment using LT, Lazar and Van Laer (1966) found no improvement in recall over $10 \mathrm{Ts}$ immediately after learning. Their data also show a loss of about one item on the first $T$. This disappeared on the subsequent 


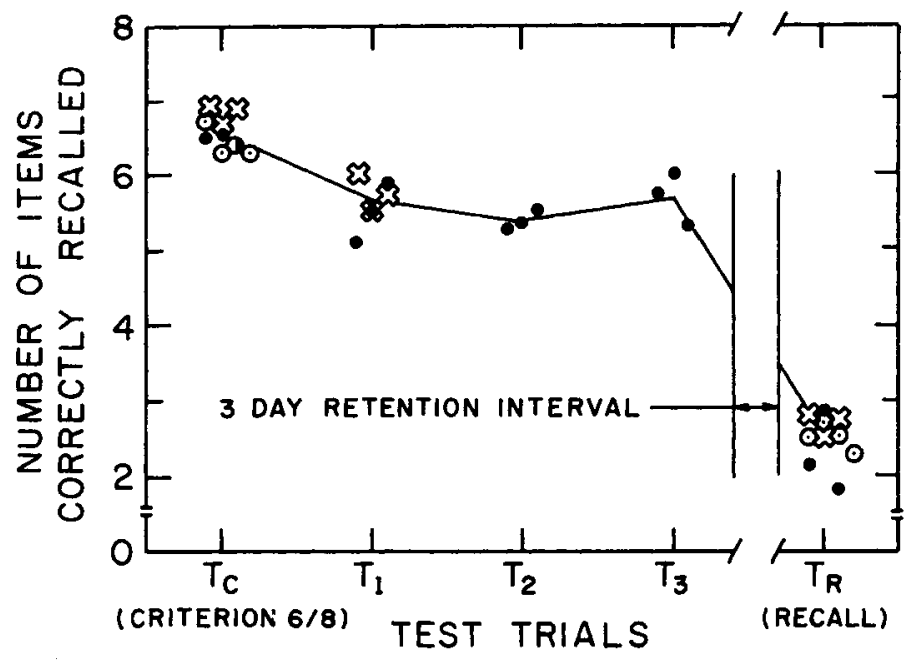

Fig. 1. Number of items correct on each test. Points are group means.

Ts. The reasons for these differences in results found using different methods warrant further study.

One reason for using the DO procedure was to control inter-pair associative strength. Table 1 shows the mean frequency of correct recalls for each A-C pairover all groups on the tests. ANOVAs of the data revealed no significant group or inter-item differences on $T_{c}, T_{1}$ or $\mathrm{T}_{2}$. Relatively equal levels of learning among the $\mathrm{A}-\mathrm{C}$ pairs was produced. However, on $T_{3}$ and $T_{r}$ reliable differences were found among items, $T_{3}: F=5.23$, df $=7 / 14, p<.01 ; T_{r}: F=2.25, d f=7 / 63, p<.05$. The fact that inter-pair differences were found after repeated Ts and in recall raises some questions about DO. It may be necessary to control the level of learning of the pairs more precisely. To do this it may be necessary to select pairs of equivalent difficulty or modify the procedure. Battig (1965, p. 6) indicates that inter-pair differences in final level of learning might be eliminated by requiring additional correct responses for difficult pairs.

Such modification may not always be necessary. Inspection of Table 1 reveals consistency in the recall frequencies of items over Ts. Generally, those having

Table 1. A-C Pairs, Their Meaningfulness $\left(a^{\prime}\right)$ and the Number of Correct Recalls for each Pair Averaged Across Groups

\begin{tabular}{|c|c|c|c|c|c|c|c|c|c|}
\hline \multirow{2}{*}{\multicolumn{2}{|c|}{ airs }} & & \multicolumn{2}{|c|}{$\begin{array}{c}\text { Rated } \\
\text { Association } \\
\text { Value }\end{array}$} & \multicolumn{4}{|c|}{$\begin{array}{c}\text { Mean Number Correct On } \\
\text { Each Test Trial }\end{array}$} & \multirow[b]{2}{*}{$T_{r}$} \\
\hline & & & $a^{\prime}$ & $a^{\prime}$ & $T_{e}$ & $\mathrm{~T}_{1}$ & $T_{2}$ & $\mathrm{~T}_{3}$ & \\
\hline (A & - & C) & (A. & C) & $n=(150)$ & $(90)$ & (45) & (45) & $(150)$ \\
\hline $\begin{array}{l}\text { QIH } \\
\text { CEO }\end{array}$ & & $\begin{array}{l}X E Y \\
X \mid Y\end{array}$ & & & & & $\begin{array}{l}8.3 \\
9.7\end{array}$ & $\begin{array}{r}10.0 \\
9.7\end{array}$ & 4.4 \\
\hline cuV & & ZOY & 1.99 & 1.50 & 14.0 & 12.3 & 11.0 & 12.0 & 6 \\
\hline TIV & & ZUY & 1.76 & 1.38 & 12.8 & 11.7 & 11.7 & 11.7 & 4.3 \\
\hline NUQ & & $X O Z$ & 1.39 & 1.15 & 11.7 & 10.2 & 9.3 & 9.0 & 4.2 \\
\hline NAJ & & YUZ & 1.65 & 1.38 & 11.8 & 10.7 & 10.0 & 11.7 & 4.6 \\
\hline $\begin{array}{l}\text { TAH } \\
\text { QEJ }\end{array}$ & & $\begin{array}{l}\text { ZEY } \\
Y I X\end{array}$ & $\begin{array}{l}1.92 \\
1.29\end{array}$ & $\begin{array}{l}1.56 \\
1.28\end{array}$ & $\begin{array}{l}13.2 \\
11.6\end{array}$ & $\begin{array}{r}11.5 \\
9.3\end{array}$ & $\begin{array}{r}12.0 \\
8.3\end{array}$ & $\begin{array}{r}11.7 \\
8.0\end{array}$ & $\begin{array}{l}6.1 \\
3.2\end{array}$ \\
\hline Means & & & 1.58 & 1.34 & 12.5 & 10.9 & 10.0 & 10.5 & 4.7 \\
\hline
\end{tabular}

somewhat higher (or lower) recall on $\mathrm{T}_{\mathrm{c}}$ show higher (or lower) recall after the retention period. This observation is supported by the lack of a significant items by Ts interaction. Therefore, since loss scores take the frequencies of correct recalls at the end of learning into account, they may be more useful estimates of the amount forgotten and of the inter-item variability. Loss scores for each item were obtained, i.e., the difference between the number of Ss in each group recalling the item on the final test trial after learning and the number recalling it after three days. ANOVA revealed no reliable differences in the amount lost per item.

No measurable improvement in recall after three days was produced by giving repeated Ts. All groups recalled about the same number of items (see Fig. 1). The use of repeated, post-criterion Ts, therefore, provides a way of measuring the equivalence of level and stability of learning between groups receiving different treatments without influencing long-term retention.

\section{References}

Battig, W. F. Procedural problems in paired-associate learning research. Psychon. Sci. Monogr. Suppl., 1965, 1, No. 1.

Butler, D. C., \& Peterson, D. E. Learning during "extinction" with paired associates. J. verbal Learn. verbal Behav., 1965, 4, 103-106.

Greenbloom, R., \& Kimble, G. A. Improvement in recall on unreinforced recall trials. J. exp. Psychol., 1966, 71, 159-160.

Lazar, G., \& Van Laer, J. Successive recall as a warm-up task for paired-adjectives. Psychon. Sci., 1966, 5, 137-138.

Noble, C. E. Measurements of association value $(a)$, rated associations $\left(a^{\prime}\right)$ and scaled meaningfulness $\left(m^{\prime}\right)$ for the $2100 \mathrm{CVC}$ combinations of the English Alphabet. Psychol. Rep., 1961, 8, 487521.

Richardson, J., \& Gropper, M. S. Learning during recall trials. Psychol. Rep., 1964, 15, 551-560.

Underwood, B. J. Degree of learning and the measurement of forgetting. J. verbal Learn. verbal Behav., 1964, 3, 112-129.

\section{Note}

1. This research was supported by Grant $802-65$ from the Air Force Office of Scientific Research. 